\title{
DETERMINACIÓN DE PARÁMETROS PARA OBTENCIÓN Y CONSERVACIÓN DE CUAJO DE BOVINO ADULTO
}

\author{
Determination of parameters for obtaining and conservation of adult bovine rennet \\ Javier S. Córdova ${ }^{1,2}$, Elizabeth Paitan ${ }^{2}$
}

${ }^{1}$ Facultad de Farmacia y Bioquímica, Universidad Nacional Mayor de San Marcos. ${ }^{2}$ Universidad Nacional del Centro del Perú

\section{RESUMEN}

El presente trabajo de investigación se realizó con el objetivo de determinar los parámetros de obtención y conservación del cuajo de bovino adulto. El abomaso seco se trozó y procedió a la extracción de la enzima con ácido clorhídrico 3 mM, pH 2,5. Se activó la solución enzimática y se filtró obteniéndose el cuajo líquido con fuerza de 1:607,59 ( 1,58) Unidades Soxhlet. El cuajo líquido se envasó en frascos de polietileno de baja densidad de color blanco lechoso, almacenándose por un mes a $4^{\circ} \mathrm{C},-7^{\circ} \mathrm{C}$ y $-198^{\circ} \mathrm{C}$, para su posterior evaluación. La fuerza del cuajo líquido en el almacenamiento a $4^{\circ} \mathrm{C}$ no dio buenos resultados, por pérdida del $38,47 \%$ de fuerza. El cuajo líquido almacenado a temperatura de $-7^{\circ} \mathrm{C}$, generó una pérdida del 30,94\% de fuerza, siendo la fuerza basal de 1:419,58 $( \pm 1,47)$ en U.S. (Unidades Soxhlet). El almacenamiento del cuajo líquido $\mathrm{a}-198^{\circ} \mathrm{C}$ (nitrógeno líquido), fue el adecuado para su conservación no generando pérdida de fuerza.

Palabras clave: Cuajo, abomaso, extracción, fuerza, poder de coagulación, enzima.

\section{SUMMARY}

The present research was conducted in order to determine the parameters of production and conservation of adult bovine rennet. Dry abomasum was chunked and proceeded to the extraction of the enzyme with hydrochloric acid 3 mM, $\mathrm{pH} 2,5$. Was activated enzyme solution and filtered to yield the liquid rennet with 1:607,59 force $( \pm 1,58)$ Soxhlet Units. Liquid rennet was filled in low density polyethylene milky white bottles and stored for one month at $4^{\circ} \mathrm{C},-7^{\circ} \mathrm{C}$ and $-198^{\circ} \mathrm{C}$, to later evaluation. The strength of liquid rennet in storage at $4^{\circ} \mathrm{C}$ did not yield good results, because loss of the $38,47^{\circ} \%$ of force. Stored liquid rennet to temperature of $-7^{\circ} \mathrm{C}$, generated a power loss of $30,94 \%$, being the basal strength of $1: 419,58( \pm 1,47)$ in U.S. (Units Soxhlet). Storage of liquid rennet to $-198^{\circ} \mathrm{C}$ (liquid nitrogen), was appropriate to preserve with power loss.

Keywords: Rennet, abomaso, extraction, forces, power of clotting, enzyme.

\section{INTRODUCCIÓN}

$\mathrm{E}$ n casi todas las comunidades campesinas de la sierra del Perú, la ganadería es la actividad principal después de la agricultura; los comuneros son criadores de ganado vacuno, ovino, caprino y, en menor proporción, porcino y equino. En consecuencia, es muy común la elaboración de queso con el uso de cuajos. Por otro lado, el cuajo preparado en forma artesanal, es elaborado utilizando procedimientos empíricos, logrando por lo general un producto con materiales extraños y contaminantes perjudiciales para su elaboración, que no posee durabilidad ni calidad, lo cual conlleva a que pequeños productores de quesos pierdan y desechen los cuajos que preparan.

Las técnicas de obtención están en función de la especie de procedencia (ternero, cabrito u oveja), e incluso varían según lugar y costumbres, por lo que la fuerza del cuajo varía. Los objetivos del presente trabajo de investigación son: determinar los parámetros de obtención y conservación del cuajo bovino adulto; determinar el flujo de obtención; evaluar la fuerza de coagulación y determinar la temperatura de conservación óptima.

\section{MATERIALES Y MÉTODOS}

El presente trabajo de investigación, se realizó en los laboratorios de Ciencia - Tecnología y Microbiología de Alimentos de la Facultad de Ingeniería en Industrias Alimentarias en el laboratorio del Instituto de Biotecnología de la Universidad Nacional del Centro del Perú y en los ambientes de Agroveterinaria "Mateos". Se utilizaron abomasos secos de bovino de 4 a 6 años de edad, adquiridos en el Mercado Modelo de Huancayo.

Se evaluaron la fuerza o poder de coagulación del cuajo líquido obtenido y almacenado durante un mes de prueba. Para la interpretación de los resultados se aplicó 
un diseño completamente al azar con arreglo factorial

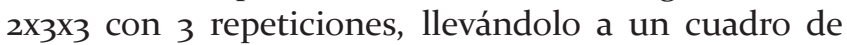
varianza, para determinar las diferencias significativas.

\section{RESULTADOS}

Se analizó la fuerza de cada solución enzimática obtenida (tabla 1).

Tabla 1. Fuerza de la solución enzimática.

\begin{tabular}{cc}
\hline Solución ácido clorhídrico & Fuerza (US)* $^{*}$ \\
\hline pH $1,5(0,032 \mathrm{M})$ & No presentó \\
pH $2,0(0,010 \mathrm{M})$ & $1: 132,96( \pm 2,58)$ \\
pH $2,5(0,003 \mathrm{M})$ & $1: 464,78( \pm 2,35)$ \\
pH $3,0(0,001 \mathrm{M})$ & $1: 338,82( \pm 1,86)$ \\
\hline
\end{tabular}

*US: unidades soxhlet

\section{Porcentaje de cloruro de sodio en la extracción}

Para extraer la enzima correspondiente, se trabajó con 3 y $5 \%(\mathrm{p} / \mathrm{v})$ de cloruro de sodio (tabla 2 ).

Tabla 2. Fuerza de la solución enzimática filtrada.

\begin{tabular}{ccc} 
Repeticiones & $\begin{array}{c}\text { Enzima extraída con } \\
\mathbf{3 \%}\end{array}$ & $\begin{array}{c}\text { Enzima extraída con } \\
\mathbf{5 \%}\end{array}$ \\
\hline r1 & $1: 498,96$ & $1: 411,66$ \\
r2 & $1: 530,97$ & $1: 487,80$ \\
r3 & $1: 510,64$ & $1: 454,55$ \\
& $1: 513,52$ & $1: 451,34$ \\
$Y_{i}$ & $( \pm 16,20)$ & $( \pm 38,17)$ \\
\hline
\end{tabular}

\section{pH en la activación}

Las soluciones enzimáticas filtradas, obtenidas después de extraer la enzima con 3 y $5 \%(\mathrm{p} / \mathrm{v})$ de cloruro de sodio, fueron llevadas a tres $\mathrm{pH}$ distintos, para activar el zimógeno contenido en ellas (tabla 3 ).

Tabla 3. Extracción de la enzima con soluciónAA ácido clorhídrico.

\begin{tabular}{ccc}
\hline $\begin{array}{c}\text { pH de } \\
\text { activación } \\
\left(\mathbf{1 8 ^ { \circ } \mathbf { C } )}\right.\end{array}$ & $\begin{array}{c}\text { Enzima extraída con } \\
\text { cloruro de sodio } \\
\text { al 3\% (p/v) }\end{array}$ & $\begin{array}{c}\text { Enzima extraída con } \\
\text { cloruro de sodio } \\
\text { al 5\% (p/v) }\end{array}$ \\
\hline 4,4 & $1: 459,48( \pm 1,34)$ & $1: 354,53( \pm 3,43)$ \\
4,6 & $1: 479,36( \pm 1,10)$ & $1: 379,65( \pm 7,51)$ \\
4,8 & $1: 607,66( \pm 7,69)$ & $1: 489,93( \pm 6,91)$ \\
\hline
\end{tabular}

Fuerza de la solución enzimática obtenida (cuajo líquido)

Después del segundo filtrado, se calculó la fuerza del cuajo líquido (tabla 4).

Tabla 4. Fuerza del cuajo líquido.

\begin{tabular}{ccc}
\hline Muestra & $\begin{array}{c}\text { Fuerza } \\
\text { (US)* }\end{array}$ & $\begin{array}{c}\text { UC** } \\
\text { (UC/ml) }\end{array}$ \\
\hline Cuajo líquido & $1: 607,59$ & 2,78 \\
$( \pm 1,58)$ & $( \pm 0,01)$ \\
\hline
\end{tabular}

*US: unidades soxhlet. **UC: unidades coagulables

\section{Efecto del almacenamiento sobre la fuerza del} cuajo líquido

El cuajo líquido se envasó y se almacenó por un mes (tabla 5).

Tabla 5. Efectos del almacenamiento sobre la fuerza del cuajo líquido.

\begin{tabular}{cccc}
\hline $\begin{array}{c}\text { Almacenamiento } \\
\text { por un mes }\end{array}$ & Fuerza (US)* & $\begin{array}{c}\text { Pérdida de } \\
\text { fuerza (\%) }\end{array}$ & $\begin{array}{c}\text { Incremento de } \\
\text { fuerza (\%) }\end{array}$ \\
\hline $4^{\circ} \mathrm{C}$ & $1: 373,83( \pm 1,60)$ & 38,47 & No presentó \\
$-7^{\circ} \mathrm{C}$ & $1: 419,58( \pm 1,47)$ & 30,94 & No presentó \\
$-198^{\circ} \mathrm{C}$ & $1: 683,76( \pm 1,45)$ & No presentó & 12,54 \\
\hline
\end{tabular}

*US: unidades soxhlet.

\section{DISCUSIÓN}

El uso de un ácido fuerte como el clorhídrico

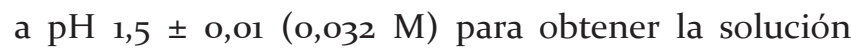
enzimática, desnaturalizó la enzima. Badui (1), menciona que la desnaturalización ácida implica la protonación de cargas de aspártato y glutámato; ambos casos impiden la interacción electrostática, lo cual provoca desnaturalización, ocasionando que la solución enzimática no presente fuerza (poder de coagulación). Se puede inferir, que a menor porcentaje de cloruro de sodio para extraer la enzima, se logra mayor fuerza, concordado con Campos ${ }^{(2)}$ y Linden y Lorient ${ }^{(3)}$. Quienes concluyen que el cloruro de sodio utilizado ejerce un efecto significativo en la extracción de la enzima.

Linden y Lorient ${ }^{(3)}$, sostienen que el zimógeno se transforma en enzima activa por proceso autocatalítico acelerado por lo iones $\mathrm{H}^{+}$; este proceso depende del $\mathrm{pH}$.

Colowicky Kaplan ${ }^{(4)}$, mencionan que la activación del zimógeno se realiza a $\mathrm{pH}$ por debajo de 5,o y da como resultado el aumento de fuerza.

En el presente estudio, al extraer la enzima con $3 \%$ de cloruro de sodio, y activarla a $\mathrm{pH} 4,8 \pm 0$,o1, se observó una fuerza de 1:607,66 $( \pm 7,69)$ unidades soxhlet (tabla 3 ), siendo el valor más alto respecto a los otros tratamientos de $\mathrm{pH}$. Este resultado es muy similar a lo señalado por Mickelsen y Ernstrom (5), quienes explican que la tasa de activación incrementa la fuerza al disminuir el $\mathrm{pH}$.

De lo previamente expuesto, se infiere que el $\mathrm{pH}$ 4,8 \pm o,ol es óptimo para la solución enzimática, lo que concuerda con lo sustentado por Godfrey y Reichelt ${ }^{(6)}$.

De acuerdo al resultado, el cuajo líquido obtuvo una fuerza de 1:607,59 $( \pm 1,58)$ unidades soxhlet (US), lo que indica que $1 \mathrm{~mL}$ de cuajo es capaz de coagular, aproximadamente, $610 \mathrm{~mL}$ de leche. El valor obtenido, 
bastante inferior a lo señalado por Alais ${ }^{(7)}$, se explica por el tipo de abomaso que se utilizó para la extracción de la enzima. En el presente estudio, este material se obtuvo a partir de animales adultos, mientras que Alais hace referencia a cuajos líquidos obtenidos a partir de animales recién nacidos.

La fuerza obtenida en la presente investigación (tabla 4) es muy similar a la lograda por Jarpa y Retamal ${ }^{(8)}$, quienes mencionan que los cuajos extraídos de animales adultos poseen fuerzas bajas.

\section{CONCLUSIONES}

1. Los parámetros óptimos para el cuajo líquido de bovino adulto tuvieron $3 \%$ de cloruro de sodio y $\mathrm{pH} 4,8$.

2. Para las condiciones del presente trabajo de investigación, el poder de coagulación del cuajo líquido de bovino adulto fue de 1:607,59 en unidades soxhlet.

3. La temperatura de conservación óptima para el cuajo liquido de bovino adulto es de $-198^{\circ} \mathrm{C}$ en tanque de nitrógeno liquido, con la cual se logró incrementar el poder de coagulación en 12,54\%. El cuajo líquido de bovino adulto presentó una concentración de quimosina de 31,59 $\mathrm{mg} / \mathrm{L}$.

\section{REFERENCIAS BIBLIOGRÁFICAS}

1. Badui S. Química de los Alimentos. $4^{\mathrm{a}}$ ed. Pearson Educación. México DF, 2008.
2. Campos C. Obtención de cuajo en polvo a partir de abomasos de cabrito (Capra sp.). [Tesis para optar el título profesional de Ingeniero en Industrias Alimentarias]. UNALM. Lima, 1990.

3. Linden G, Lorient D. Bioquímica agroindustrial: Revalorización alimentaria de la producción agrícola. $1^{\mathrm{a}}$ ed. acribia. Zaragoza, 1996.

4. Colowick S, Kaplan N. Methods in Enzimology peptide growth factors. Journal of Steroid Biochemistry 1989; 32(2): 336-7.

5. Mickelsen R, Ernstrom C. Effect of $\mathrm{pH}$ on the stability of rennin-porcine pepsin blends. Journal of Dairy Science 1972; 55(3): 294-7.

6. Godfrey T, Reichelt J. Industrial enzymology: the application of enzymes in industry. $1^{\text {a }}$ ed. Nature Press. New York, 1983.

7. Alais Ch. Ciencia de la leche. $5^{\mathrm{a}}$ ed. Continental. México DF, 1984 .

8. Jarpa J, Retamal E. Efecto de la pasteurización, adición de fermento láctico y de cuajo en la calidad microbiológica y organoléptica del queso de cabra. [Tesis para optar el Título de Ingeniero Agronomo]. Facultad de Ciencias Agrarias y Forestales. Escuela de Agronomía, Universidad de Chile. Santiago de Chile, 1985. p. 184.

\section{Correspondencia}

Nombre: $\quad$ Ing. Javier Saúl Córdova Ramos

Dirección: Jr. Puno 1002 - Lima o1 - Perú

E-mail: $\quad$ javier.cordova.ramos@hotmail.com 